\title{
nature
}

\section{When to believe the unbelievable}

An article in this week's issue describes observations for which there is no present physical basis. There are good and particular reasons why prudent people should, for the time being, suspend judgement.

INEXPLICABLE observations are not always signs of the supernatural. That is what readers of the remarkable article on page 816 should keep in mind. They should also remember that Avogadro's number, the number of molecules in a gram molecule of material, is roughly $6.23 \times 10^{23}$, which naturally implies that most of the experiments with antibody solution reported by Professor J. Benveniste and his colleagues have been carried out in the literal absence of antibody molecules. For what the article shows is that it is possible to dilute an aqueous solution of an antibody virtually indefinitely without the solution losing its biological activity. Or rather, there is a surprising rhythmic fluctuation in the activity of the solution. At some dilutions, the activity falls off; on further dilution, it is restored.

There is no objective explanation of these observations. Nor is there much comfort for anybody in the explanation offered at the end of the article - that antibody molecules once embodied in water leave their internal marks, as ghosts of a kind, on its molecular structure - for there is no evidence of any other kind to suggest that such behaviour may be within the bounds of possibility. Indeed, during the long period since this article was first submitted to Nature, it has been plain that Benveniste has been as puzzled as many of those who have read his article by the data he reports. On many occasions, he has responded to referees' suggestions at great inconvenience to himself. When told, for example, that the experiments should be repeated at an independent laboratory, he arranged for this to be done.

One of the purposes that will be served by publishing the article will be to provide an authentic account of this work for the benefit of those, especially in France, who have gathered rumours of it from the popular press. Another is that vigilant members of the scientific community with a flair for picking holes in other people's work may be able to suggest further tests of the validity of the conclusions.

Certainly there can be no justification, at this stage, for an attempt to use Benveniste's conclusions for the malign purposes to which they might be put. There are some obvious dangers. In homoeopathic medicine, for example, which works on the principle that very small concentrations of appropriate products may have consequences that far outweigh those expected of them, there will be a natural inclination to welcome Benveniste's article as aid and comfort, but that would be premature, probably mistaken. It will be time for celebrations of that kind only when a lot more water has run underneath this bridge.

But, those of supernatural inclinations will protest, is it not grossly unfair that science should put aside, even temporarily, some surprising and unexpected observations (such as these) while apparently welcoming others which are no less surprising (such as the recent suggestion that there may be a 'fifth force' between material objects)? The explanation is simple, but, perhaps for that reason, not widely understood. It is entirely possible for physicists to welcome the notion of the fifth force because it would be a novel happening which could nevertheless be accommodated within the accepted framework of science. Benveniste's observations, on the other hand, are startling not merely because they point to a novel phenomenon, but because they strike at the roots of two centuries of observation and rationalization of physical phenomena. Where, for example, would elementary principles such as the Law of Mass Action be if Benveniste is proved correct? The principle of restraint which applies is simply that, when an unexpected observation requires that a substantial part of our intellectual heritage should be thrown away, it is prudent to ask more carefully than usual whether the observation may be incorrect.

\section{Criminalizing research}

\section{West Germany seems bent on a restrictive law on embryo research.}

THE efforts of West Germany's scientific organizations - Max Planck Society, Deutsche Forschungsgemeinschaft (DFG) - to prevent the passage of a restrictive Embryo Protection Law have apparently missed the mark (see page 791). Even if there were a party brave enough to amend the Justice Ministry's proposed ban on embryo research, it is hard to imagine that it could win a majority. More probably, given the prevailing mood in West Germany that "One shouldn't meddle with the Lord's handiwork", such a course would invite electoral trouble. Yet West Germany appears content with legal abortion: an eight-hour debate at the ruling Christian Democrats' party congress in midJune led merely to an affirmation of the status quo. Is it not a paradox that research should be singled out as a scapegoat?

Much the same, of course, is happening in Britain, where the promised bill on embryo research seems certain to feature in the next session of Parliament, and where abortion remains a contentious issue. But there are two reasons why West Germany may be impelled towards meticulous central regulation rather than allowing researchers to police themselves.

First, there are the abuses of the past. Contemporary researchers may complain that they are being punished for acts for which they are not responsible, but, sadly, West German science, like its foreign relations and its military policy, still lives in the shadow of Nazi crimes. Second, the West German legal system differs dramatically from the Anglo-Saxon system. Whereas the Anglo-Saxon system applies a "principle of opportunity" allowing prosecutors broad discretion in decisions whether or not to prosecute a case, the German system forces a prosecutor to act if there is even a suspicion that a law has been broken. West German courts are not bound by legal precedents, as in Britain or the United States, so that legislators have no choice but to express their intentions in the minutest detail.

It will be small consolation for West German researchers that their work may be curtailed because of history and the legal system. At first, the Max Planck society and the DFG seemed incredulous that such a thing could happen; after all, "freedom of research" was guaranteed by the West German constitution. But now these organizations realize that research takes second place to human dignity, whatever that may mean. That, at least, is how the Justice Ministry sees the issue. But how soon will it be before people in West Germany appreciate that embryo research may, in due course, enhance that same ideal, perhaps by helping to rid people of undignifying genetic diseases? 